\title{
Aqueous Solubility of Piperazine and 2-Amino-2-methyl-1-propanol plus Their Mixtures Using an Improved Freezing-Point Depression Method
}

Fosbøl, Philip Loldrup; Neerup, Randi; Waseem Arshad, Muhammad; Tecle, Zacarias; Thomsen, Kaj

Published in:

Journal of Chemical and Engineering Data

Link to article, DOI:

$10.1021 / \mathrm{je} 200959 \mathrm{~m}$

Publication date:

2011

Document Version

Publisher's PDF, also known as Version of record

Link back to DTU Orbit

Citation (APA):

Fosbøl, P. L., Neerup, R., Waseem Arshad, M., Tecle, Z., \& Thomsen, K. (2011). Aqueous Solubility of Piperazine and 2-Amino-2-methyl-1-propanol plus Their Mixtures Using an Improved Freezing-Point Depression Method. Journal of Chemical and Engineering Data, 56(12), 5088-5093. https://doi.org/10.1021/je200959m

\section{General rights}

Copyright and moral rights for the publications made accessible in the public portal are retained by the authors and/or other copyright owners and it is a condition of accessing publications that users recognise and abide by the legal requirements associated with these rights.

- Users may download and print one copy of any publication from the public portal for the purpose of private study or research.

- You may not further distribute the material or use it for any profit-making activity or commercial gain

- You may freely distribute the URL identifying the publication in the public portal 


\title{
Aqueous Solubility of Piperazine and 2-Amino-2-methyl-1-propanol plus Their Mixtures Using an Improved Freezing-Point Depression Method
}

\author{
Philip Loldrup Fosbøl,* Randi Neerup, Muhammad Waseem Arshad, Zacarias Tecle, and Kaj Thomsen \\ Department of Chemical and Biochemical Engineering, Center for Energy Resources Engineering (CERE), Technical University of \\ Denmark (DTU), Søltofts Plads, Building 229, DK-2800 Kongens Lyngby, Denmark
}

\begin{abstract}
In this work the solid-liquid equilibrium (SLE) and freezing-point depression (FPD) in the electrolytic binary aqueous systems piperazine (PZ, CAS No. 110-85-0) and aqueous 2-amino-2-methyl-1-propanol (AMP, CAS No. 124-68-5) were measured. The FPD and solubility were also determined in the ternary AMP-PZ- $\mathrm{H}_{2} \mathrm{O}$ system. A method was developed by which solubility can be determined at higher temperatures using the FPD setup. A total of 86 data points are listed in the full concentration range from $(-35$ to 90$){ }^{\circ} \mathrm{C}$. The solid phases piperazine hexahydrate $\left(\mathrm{PZ} \cdot 6 \mathrm{H}_{2} \mathrm{O}\right)$, piperazine hemihydrate $\left(\mathrm{PZ} \cdot 1 / 2 \mathrm{H}_{2} \mathrm{O}\right)$, and anhydrous $\mathrm{PZ}$ precipitated during the experiments. The data can be used in the formulation, prevention, or intentional formation of slurries in piperazine solvents for promoting $\mathrm{CO}_{2}$ capture using absorption and desorption.
\end{abstract}

\section{INTRODUCTION}

$\mathrm{CO}_{2}$ capture is an openly debated topic for carbon emission reduction to reduce pollution by greenhouse gases. Process streams containing carbon dioxide can be cleaned by absorption in aqueous liquid solvents. Amines, strong bases, or combination of the two are typically used as active components. The low heats of absorption and desorption are design criteria that reduce the cost of energy in regeneration of the solvent. This is obtained by using sterically hindered amines. The result is often slow reaction kinetics between the solvent and $\mathrm{CO}_{2}$. Consequently piperazine $(\mathrm{PZ})$ is being used in solution formulation to create an enhanced $\mathrm{CO}_{2}$ capture solvent. $\mathrm{PZ}$ can be used with both amine and potash solutions $\left(\mathrm{K}_{2} \mathrm{CO}_{3}\right)$ to increase the rate of absorption and thereby promote the $\mathrm{CO}_{2}$ capture.

A lower PZ concentration was typically used in literature. Recently the scope has changed, and PZ is now being used at higher concentrations. On increasing the concentration, the solubility limit of PZ is being reached, especially during winter temperatures and even up to room temperature. The unexpected formation of slurries and solids downstream may create unforeseen process conditions, decrease efficiency, and create clogging which will result in unfortunate hazardous operations. In general it could be interesting to provoke the formation of $\mathrm{CO}_{2}$ containing solids and thereby facilitate and increase the capacity of the capture solvent. $\mathrm{CO}_{2}$ deprived solids are rarely preferable in terms of $\mathrm{CO}_{2}$ capture.

The aim of this work is to determine the solid-liquid phase boundary in the two binary $\mathrm{PZ}-\mathrm{H}_{2} \mathrm{O}$ and $\mathrm{AMP}-\mathrm{H}_{2} \mathrm{O}$ systems and also in the ternary $\mathrm{AMP}-\mathrm{PZ}-\mathrm{H}_{2} \mathrm{O}$ system. 2-Amino2-methyl-1-propanol (AMP) is a sterically hindered amine. $\mathrm{CO}_{2}$ absorption in AMP solutions can be promoted by adding PZ.

An additional goal of this work was to enhance the utilization of freezing-point depression (FPD) equipment developing a method for the purpose of studying solid-liquid equilibrium (SLE) behavior in solutions precipitating solids other than ice.
PZ is a compound which has a variety of applications; for example, it has been used for animal and human intake in the treatment of roundworm infections as an anthelmintic. ${ }^{1,2}$

The SLE phase boundaries of the aqueous PZ system were examined very early by Berthelot, ${ }^{3}$ further by Rosso and Carbonnel, ${ }^{4}$ and in summary by Carbonnel and Rosso. ${ }^{5}$ Berthelot ${ }^{3}$ stated the existence of the hexahydrate $\mathrm{PZ} \cdot 6 \mathrm{H}_{2} \mathrm{O}$, the hemihydrate $\mathrm{PZ} \cdot 1 / 2 \mathrm{H}_{2} \mathrm{O}$, and possibly a monohydrate. The differential scanning calorimetry (DSC) analysis by Rosso and Carbonnel ${ }^{4}$ confirmed the formation of the following PZ solid hydrate phases, hexahydrate, hemihydrate, and anhydrous PZ with the equilibrium reactions:

$$
\begin{aligned}
& \mathrm{PZ} \cdot 6 \mathrm{H}_{2} \mathrm{O}(\mathrm{s}) \rightleftarrows \mathrm{PZ}(\mathrm{aq})+6 \mathrm{H}_{2} \mathrm{O}(\mathrm{l}) \\
& \mathrm{PZ} \cdot \frac{1}{2} \mathrm{H}_{2} \mathrm{O}(\mathrm{s}) \rightleftarrows \mathrm{PZ}(\mathrm{aq})+\frac{1}{2} \mathrm{H}_{2} \mathrm{O}(\mathrm{l}) \\
& \mathrm{PZ}(\mathrm{s}) \rightleftarrows \mathrm{PZ}(\mathrm{aq})
\end{aligned}
$$

Rosso and Carbonnel especially note that the system has two eutectic points, at $-1{ }^{\circ} \mathrm{C}$ between ice and hexahydrate and at $33{ }^{\circ} \mathrm{C}$ between hexahydrate and hemihydrate, including a peritectic point at $58{ }^{\circ} \mathrm{C}$ at the intersection between hemihydrate and anhydrous PZ. The hexahydrate melts at $44{ }^{\circ} \mathrm{C}$, and anhydrous PZ melts at $104{ }^{\circ} \mathrm{C}$, as determined by Berthelot, ${ }^{3}$ Schwarzenbach, ${ }^{6}$ and Rosso and Carbonnel. ${ }^{4}$ A more accurate anhydrous melting point was estimated by Witschonke ${ }^{7}$ of (111.4 and 111) ${ }^{\circ} \mathrm{C}$ by Hetzer et al., ${ }^{8}$ which is in line with the chemical supplier of this work. Rosso and Carbonnel ${ }^{4}$ present a

Special Issue: Kenneth N. Marsh Festschrift

Received: September 5, 2011

Accepted: November 8, 2011

Published: November 14, 2011 
complete SLE phase diagram of the aqueous PZ system with an accuracy of $\pm 1{ }^{\circ} \mathrm{C}$.

More recently PZ precipitation has received attention during $\mathrm{CO}_{2}$ capture studies. Bishnoi ${ }^{9}$ and Bishnoi and Rochelle ${ }^{10}$ studied SLE by dissolution of the anhydrous PZ until equilibrium, and titration was applied in the analysis of the liquid phase which was repeated by Muhammad et al. ${ }^{11}$ Hilliard $^{12}$ applied a DSC technique similar to Rosso and Carbonnel. ${ }^{4}$

No apparent studies are available on SLE in the binary $\mathrm{AMP}-\mathrm{H}_{2} \mathrm{O}$ system or in the ternary $\mathrm{AMP}-\mathrm{PZ}-\mathrm{H}_{2} \mathrm{O}$ system.

On the addition of $\mathrm{CO}_{2}$ the $\mathrm{PZ}$ equilibria become very complex. The speciation in the liquid phase will result in a number of new species. Carbonates, bicarbonates, and carbamates are formed. PZ has, opposite MEA (monoethanol amine), the ability to form several different carbamates. ${ }^{10,13-15}$ This is noteworthy in studying PZ systems.

\section{EXPERIMENTAL DETAILS}

2.1. Materials. White anhydrous $\mathrm{PZ}$ was purchased from Fluka at a BioUltra grade, $>99.0 \%$, and amorphous AMP obtained through Acros at $99 \%$ was used without further purification. The liquid solutions were mixed from the pure chemicals using deionized water with a maximum conductivity of $0.2 \mu \mathrm{S}$.

2.2. Apparatus. The FPDs of the solutions were measured using the apparatus by Fosbøl et al. ${ }^{16}$ The solubility measurements were conducted using the SLE titration apparatus described in detail by Fosbøl et al. ${ }^{17}$ As outlined below, a new method was developed for which the FPD apparatus could be used for the determination of solubility to obtain results equivalent to the data determined from titration.

2.3. Experimental Method. The freezing point of the solutions was determined using the technique outlined by Fosbøl et al. ${ }^{16}$ The SLE behavior for solutions precipitating solids other than ice were analyzed using two methods. The first method performed was the use of a titration setup described by Fosbøl et al. ${ }^{17}$ The second method was to determine SLE by the FPD method described below.

The titration results were postprocessed using method III of Fosbøl et al. ${ }^{18} \mathrm{PZ}$ has two equivalence points similar to titration of aqueous $\mathrm{Na}_{2} \mathrm{CO}_{3}$ forming $\mathrm{PZH}^{+}$and $\mathrm{PZH}_{2}{ }^{2+}$, and AMP has one, protolysing to $\mathrm{AMPH}^{+}$. Seeding the solution by $\mathrm{PZ} \cdot 6 \mathrm{H}_{2} \mathrm{O}$ was done for few mixtures which did not precipitate $\mathrm{PZ} \cdot 6 \mathrm{H}_{2} \mathrm{O}$ as expected.

SLE by FPD is a new method developed in this study. It builds on the principles of the visual polythermal method. Here a modified Beckman FPD apparatus equivalent to the setup by Fosbøl et al. ${ }^{16}$ was used to accurately determine the salt solubility. The apparatus itself was not changed, but the method for determining the phase change was altered. The phase change cannot be recognized the same way Fosbøl et al. ${ }^{16}$ described it for ice. The heat developed during phase transition is simply not sufficient to show the same distinct temperature phenomena. This is especially the case for the hydrate precipitation. The reaction rate and the reaction enthalpy need to be reasonably fast and exothermic.

To maintain accuracy, the solubility can be determined by visually inspecting the FPD sample glass while melting the solutions. Initially the solution is cooled until onset of precipitation. The solution is then slowly melted by holding it in air at room temperature while stirring. It can also be lowered into a beaker containing hot water with a temperature higher than the

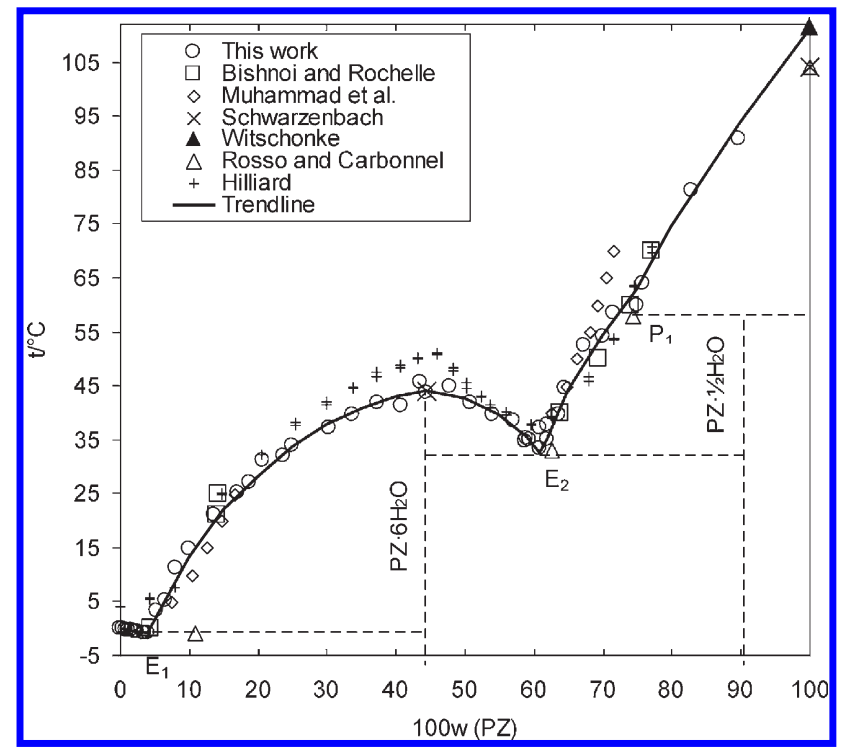

Figure 1. SLE diagram of solid precipitation in the binary $\mathrm{PZ}-\mathrm{H}_{2} \mathrm{O}$ system as a function of temperature at atmospheric conditions. The line indicates the trend of the data.

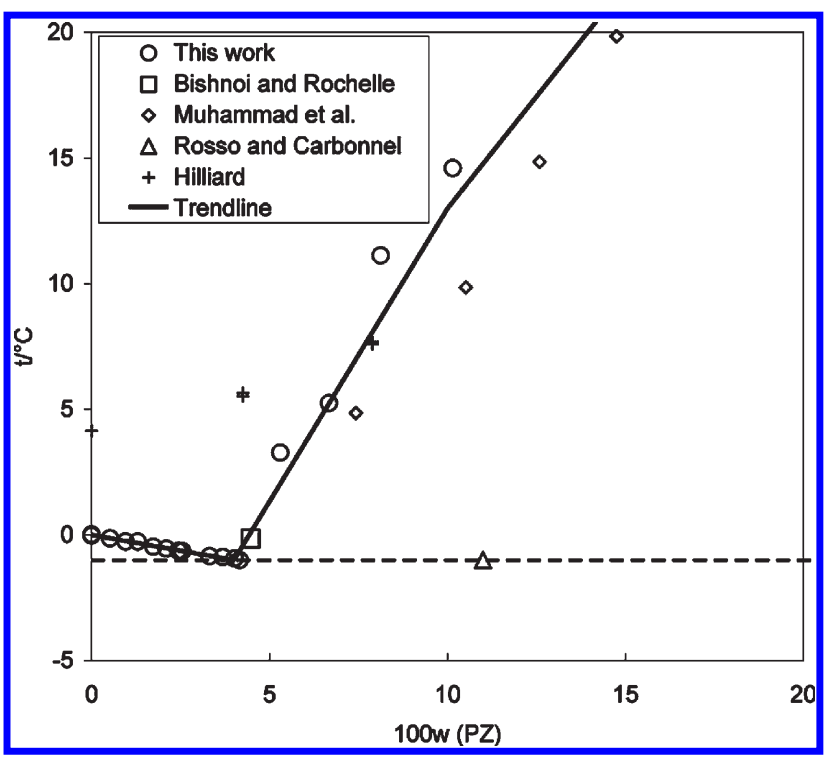

Figure 2. SLE diagram of solid precipitation in the binary $\mathrm{PZ}-\mathrm{H}_{2} \mathrm{O}$ system for $w(\mathrm{PZ})<0.2$ as a function of temperature at atmospheric conditions. The line indicates the trend of the data.

melting point of the mixture. Using the FPD temperature probe, the solubility point is determined by the disappearance of the crystals where the solution becomes clear on heating. A typical accuracy of (0.05 to 0.2$) \mathrm{K}$ is obtained using this method. The reproducibility is obtained by consecutively heating and cooling the sample past the solid-liquid phase boundary.

\section{RESULTS AND DISCUSSION}

The measured solubility data for PZ in water are shown in Figures 1 and 2. Figure 2 focuses on the low concentration range. Solubility data from other studies are also shown in the two figures. The corresponding measurements performed in this work are listed in Table 1. The measured FPD and the solubilities 
Table 1. Solubility in the PZ-Water System as a Function of Temperature at Atmospheric Conditions Determined by FPD, SLE by FPD, and Titration Methods

\begin{tabular}{|c|c|c|c|c|c|c|c|c|c|}
\hline$t$ & $w(\mathrm{PZ})$ & $\sigma_{t}^{a}$ & $\sigma_{\mathrm{w}}{ }^{a}$ & & $t$ & $w(\mathrm{PZ})$ & $\sigma_{t}^{a}$ & $\sigma_{\mathrm{w}}{ }^{a}$ & \\
\hline${ }^{\circ} \mathrm{C}$ & $\mathrm{g} \cdot(\mathrm{g} \text { total })^{-1}$ & ${ }^{\circ} \mathrm{C}$ & $\mathrm{g} \cdot(\mathrm{g} \text { total })^{-1}$ & $\mathrm{SF}^{b}$ & ${ }^{\circ} \mathrm{C}$ & $\mathrm{g} \cdot(\mathrm{g} \text { total })^{-1}$ & ${ }^{\circ} \mathrm{C}$ & $\mathrm{g} \cdot(\mathrm{g} \text { total })^{-1}$ & $\mathrm{SF}^{b}$ \\
\hline-0.129 & 0.00521 & 0.005 & & ice & 41.75 & 0.3745 & 0.036 & & $\mathrm{PZ} \cdot 6 \mathrm{H}_{2} \mathrm{O}$ \\
\hline-0.261 & 0.00953 & 0.007 & & ice & 41.3 & 0.409 & & 0.007 & $\mathrm{PZ} \cdot 6 \mathrm{H}_{2} \mathrm{O}$ \\
\hline-0.259 & 0.01297 & 0.01 & & ice & 45.6 & 0.4356 & 0.16 & & $\mathrm{PZ} \cdot 6 \mathrm{H}_{2} \mathrm{O}$ \\
\hline-0.467 & 0.01738 & 0.002 & & ice & 43.745 & 0.4437 & 0.24 & & $\mathrm{PZ} \cdot 6 \mathrm{H}_{2} \mathrm{O}$ \\
\hline-0.543 & 0.02100 & 0.003 & & ice & 44.64 & 0.4782 & 0.096 & & $\mathrm{PZ} \cdot 6 \mathrm{H}_{2} \mathrm{O}$ \\
\hline-0.629 & 0.02440 & 0.004 & & ice & 41.79 & 0.5093 & 0.08 & & $\mathrm{PZ} \cdot 6 \mathrm{H}_{2} \mathrm{O}$ \\
\hline-0.626 & 0.02468 & 0.007 & & ice & 39.6 & 0.5396 & 0.18 & & $\mathrm{PZ} \cdot 6 \mathrm{H}_{2} \mathrm{O}$ \\
\hline-0.639 & 0.02551 & 0.011 & & ice & 38.5 & 0.5699 & 0.12 & & $\mathrm{PZ} \cdot 6 \mathrm{H}_{2} \mathrm{O}$ \\
\hline-0.845 & 0.03315 & 0.006 & & ice & 34.5 & 0.5885 & 0.24 & & $\mathrm{PZ} \cdot 6 \mathrm{H}_{2} \mathrm{O}$ \\
\hline-0.876 & 0.03690 & 0.024 & & ice & 35.19 & 0.5903 & 0.03 & & $\mathrm{PZ} \cdot 6 \mathrm{H}_{2} \mathrm{O}$ \\
\hline-0.931 & 0.04017 & 0.011 & & ice & 34.8 & 0.595 & & 0.005 & $\mathrm{PZ} \cdot 6 \mathrm{H}_{2} \mathrm{O}$ \\
\hline-0.999 & 0.04161 & 0.005 & & ice & 33.4 & 0.6090 & & 0.0005 & $\mathrm{PZ} \cdot 6 \mathrm{H}_{2} \mathrm{O}$ \\
\hline 3.28 & 0.0530 & 0.096 & & $\mathrm{PZ} \cdot 6 \mathrm{H}_{2} \mathrm{O}$ & 37.03 & 0.6097 & 0.06 & & $\mathrm{PZ} \cdot 1 / 2 \mathrm{H}_{2} \mathrm{O}$ \\
\hline 5.25 & 0.0667 & & 0.0002 & $\mathrm{PZ} \cdot 6 \mathrm{H}_{2} \mathrm{O}$ & 37.55 & 0.619 & & 0.007 & $\mathrm{PZ} \cdot 1 / 2 \mathrm{H}_{2} \mathrm{O}$ \\
\hline 11.13 & 0.0812 & 0.05 & & $\mathrm{PZ} \cdot 6 \mathrm{H}_{2} \mathrm{O}$ & 34.85 & 0.619 & & 0.010 & $\mathrm{PZ} \cdot 1 / 2 \mathrm{H}_{2} \mathrm{O}$ \\
\hline 14.6 & 0.1015 & & 0.0005 & $\mathrm{PZ} \cdot 6 \mathrm{H}_{2} \mathrm{O}$ & 39.6 & 0.637 & & 0.004 & $\mathrm{PZ} \cdot 1 / 2 \mathrm{H}_{2} \mathrm{O}$ \\
\hline 20.9 & 0.1375 & 0.08 & & $\mathrm{PZ} \cdot 6 \mathrm{H}_{2} \mathrm{O}$ & 44.5 & 0.65 & & 0.02 & $\mathrm{PZ} \cdot 1 / 2 \mathrm{H}_{2} \mathrm{O}$ \\
\hline 25.0 & 0.1710 & & 0.0009 & $\mathrm{PZ} \cdot 6 \mathrm{H}_{2} \mathrm{O}$ & 52.47 & 0.6720 & 0.09 & & $\mathrm{PZ} \cdot 1 / 2 \mathrm{H}_{2} \mathrm{O}$ \\
\hline 26.98 & 0.1884 & 0.05 & & $\mathrm{PZ} \cdot 6 \mathrm{H}_{2} \mathrm{O}$ & 54.1 & 0.70 & & 0.01 & $\mathrm{PZ} \cdot 1 / 2 \mathrm{H}_{2} \mathrm{O}$ \\
\hline 31.0 & 0.208 & & 0.01 & $\mathrm{PZ} \cdot 6 \mathrm{H}_{2} \mathrm{O}$ & 58.52 & 0.7153 & 0.09 & & $\mathrm{PZ}$ \\
\hline 31.94 & 0.2367 & 0.06 & & $\mathrm{PZ} \cdot 6 \mathrm{H}_{2} \mathrm{O}$ & 59.9 & 0.7494 & 0.17 & & $\mathrm{PZ}$ \\
\hline 33.88 & 0.2510 & 0.05 & & $\mathrm{PZ} \cdot 6 \mathrm{H}_{2} \mathrm{O}$ & 63.9 & 0.759 & & 0.006 & $\mathrm{PZ}$ \\
\hline 37.0 & 0.304 & & 0.001 & $\mathrm{PZ} \cdot 6 \mathrm{H}_{2} \mathrm{O}$ & 81.07 & 0.8290 & 0.04 & & $\mathrm{PZ}$ \\
\hline 39.45 & 0.338 & & 0.01 & $\mathrm{PZ} \cdot 6 \mathrm{H}_{2} \mathrm{O}$ & 90.7 & 0.8977 & 0.25 & & $\mathrm{PZ}$ \\
\hline
\end{tabular}

from equilibrium analysis using FPD setup and titration are given. The standard deviations of the measurements are shown along with the information of the solid phases.

A repeatability, often better than $0.01 \mathrm{~K}$, was obtained for the FPD analysis, which indicates a good accuracy.

Standard deviations up to $0.2 \mathrm{~K}$ were observed for cases using the above SLE by FPD method for concentrations higher than the ice $-\mathrm{PZ} \cdot 6 \mathrm{H}_{2} \mathrm{O}$ eutectic point.

A maximum standard deviation of the titration experiments is $\sigma(w(\mathrm{PZ}))= \pm 0.02$ where a typical value is $\sigma(w(\mathrm{PZ}))= \pm 0.001$.

Comparing the two methods of FPD and titration, the qualitative accuracy between experimental points seem to be varying. It is expected that the accuracy is similar to the reproducibility for the cases precipitating ice. For the highly concentrated solutions the accuracy seems to be lower on visually inspecting Figures 1 and 2, possibly in the order of $0.1 \mathrm{~K}$ to $1 \mathrm{~K}$ and in worst cases up to $2 \mathrm{~K}$ where the solubility determination is difficult from an experimental point of view.

3.1. $\mathrm{PZ}-\mathrm{H}_{2} \mathrm{O}$ System. Figure 1 shows the two eutectic points, $E_{1}$ and $E_{2}$, in addition to the peritectic point $P_{1}$. The trend of the curve is similar to the hydrate formation in a number of inorganic $\mathrm{SLE}$ systems. Ice is formed below $w(\mathrm{PZ})=0.04$. Amorphous $\mathrm{PZ} \cdot 6 \mathrm{H}_{2} \mathrm{O}$ precipitates at $0.04<w(\mathrm{PZ})<0.61$, followed by $\mathrm{PZ} \cdot 1 / 2 \mathrm{H}_{2} \mathrm{O}$ at $0.61<w(\mathrm{PZ})<0.71$, and anhydrous $\mathrm{PZ}$ for $w(\mathrm{PZ})>0.71$.

Starting up a capture plant at winter type conditions may create difficulties with respect to slurries and clogging using a piperazine solvent. The diagram in Figure 2 shows that aqueous piperazine freezes completely to solid below $-1{ }^{\circ} \mathrm{C}$. Precipitation may even take place at approximately $w(\mathrm{PZ})=0.17$ at $25^{\circ} \mathrm{C}$ as plotted in Figure 1. An expected local maximum in the solubility is observed by the melting point of $\mathrm{PZ} \cdot 6 \mathrm{H}_{2} \mathrm{O}$. Heating the liquid above $45^{\circ} \mathrm{C}$ will cause the dissolution of $\mathrm{PZ}$ up to $w(\mathrm{PZ})=0.65$, whereas further heating results in a relatively small solubility increase. For concentrations of $w(\mathrm{PZ})>0.44$, the solutions become completely solid below $32{ }^{\circ} \mathrm{C}$ indicated by the dotted line below $\mathrm{E}_{2}$ in Figure 1 . The solubility points in the vicinity of $\mathrm{E}_{2}$ at $0.59<w(\mathrm{PZ})<0.65$ are especially difficult to determine. The precipitate makes the solution look like milk with small crystals creeping up the sample container surfaces. It is not fully established whether hemihydrate is in stable equilibrium with the saturated liquid close to concentrations of $\mathrm{E}_{2}$ or it could be the monohydrate. For $w(\mathrm{PZ})>0.65$ hydrous amorphous $\mathrm{PZ}$ flakes are formed.

To prevent any solid formation in an aqueous $\mathrm{PZ}$ system, it is recommended to keep PZ concentrations low, below $w(\mathrm{PZ})=$ 0.04 , and above a temperature of $0{ }^{\circ} \mathrm{C}$.

Figures 1 and 2 include the data of previous works on the aqueous PZ SLE behavior. The initial studies by Berthelot ${ }^{3}$ and Schwarzenbach ${ }^{6}$ indicated the melting point of $\mathrm{PZ}$ hexahydrate to be $44{ }^{\circ} \mathrm{C}$ equivalent to this study and the melting point of pure $\mathrm{PZ}$ to be $104{ }^{\circ} \mathrm{C}$, even though a more accurate value of $111^{\circ} \mathrm{C}$ was published by Witschonke. ${ }^{7}$ The most comprehensive and accurate study was carried out by Rosso and Carbonnel; ${ }^{4}$ 


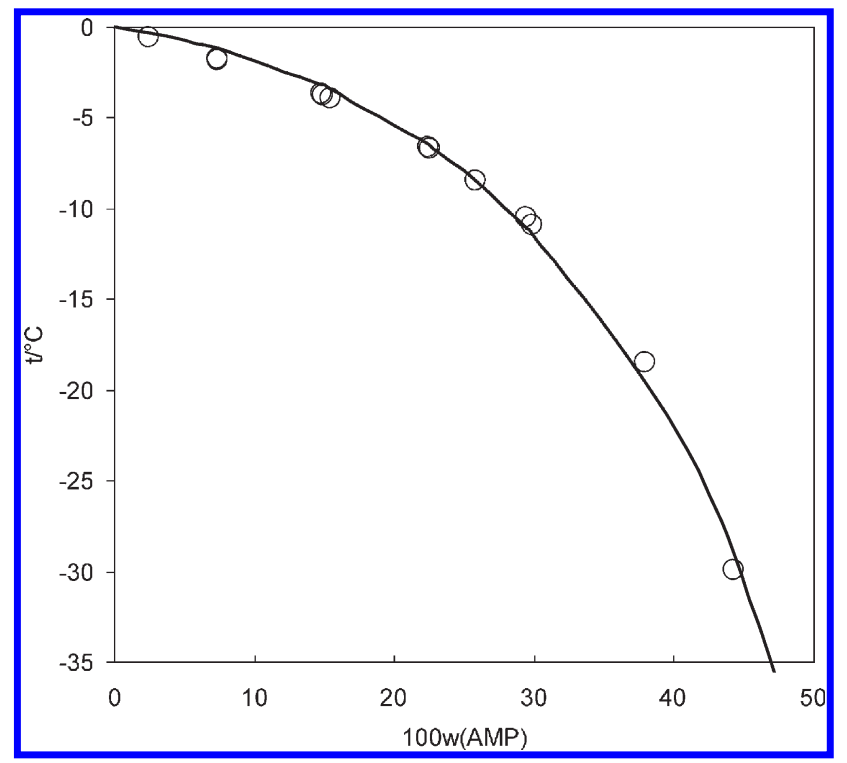

Figure 3. SLE diagram of ice precipitation in the binary $\mathrm{AMP}-\mathrm{H}_{2} \mathrm{O}$ system as a function of temperature at atmospheric conditions. The line indicates the trend of the data.

unfortunately they only tabulated the eutectic and peritectic points $\left(E_{1}, E_{2}, P_{1}\right)$ as indicated in the figure. Their original work follows the drawn trend line, except at low PZ concentrations $w(\mathrm{PZ})<0.25$. Especially their eutectic point determined at $w(\mathrm{PZ})=0.11$ and $-1{ }^{\circ} \mathrm{C}$ deviates as shown in Figure 2. In this work the eutectic point was determined to be $w(\mathrm{PZ})=0.042$ and $-1.00{ }^{\circ} \mathrm{C}$.

The work performed by Hilliard ${ }^{12}$ deviates at subsections of the SLE boundary compared to the trend line in Figures 1 and 2. This could be due to the critical control needed of the enforced temperature ramp in their used DSC. If a rate too high is used, the measurements may become inaccurate. This is noted by the determined melting point of ice by Hilliard ${ }^{12}$ which is $4.16^{\circ} \mathrm{C}$, and the melting point increases while $\mathrm{PZ}$ is added. This is unexpected from the thermophysical point of view. Hilliard's data points are approximately $7 \mathrm{~K}$ too high for most of the $\mathrm{PZ} \cdot 6 \mathrm{H}_{2} \mathrm{O}$ region compared to the trend line and the measurements of this work and of Schwarzenbach. ${ }^{6}$ On the other hand, the data by Hilliard for $w(\mathrm{PZ})>0.52$ resemble the solubilities listed in Table 1. The compositions measured by Bishnoi and Rochelle ${ }^{10}$ compare well to the measurements of this work even though the discontinuity they mention does not exist in practice. On the contrary, Muhammad et al. ${ }^{11}$ listed the solubilities in terms of mole fractions which are not comparable to any of the shown works. By instead converting their measured molarities using the density correlation of Cullinane, ${ }^{19}$ the results shown in Figure 1 were obtained. Deviations are observed in most part of the data points, and the curvature is concave whereas a convex trend would be expected.

There is a need for more and accurate experimental data points on the solubility in the complete binary $\mathrm{PZ}-\mathrm{H}_{2} \mathrm{O}$ system even though the solubility is qualitatively given by Rosso and Carbonnel. ${ }^{4}$ The solubility in the region $w(\mathrm{PZ})>0.77$ and below $11{ }^{\circ} \mathrm{C}$ is vaguely studied and needs to be further investigated, even though it may be irrelevant for $\mathrm{CO}_{2}$ capture using this high concentration.

3.2. AMP $-\mathrm{H}_{2} \mathrm{O}$ System. The FPD behavior of the binary AMP $-\mathrm{H}_{2} \mathrm{O}$ system is shown in Figure 3 for $t>-35^{\circ} \mathrm{C}$ as listed
Table 2. Solubility in the AMP-Water System as a Function of Temperature at Atmospheric Conditions Determined by FPD

\begin{tabular}{|c|c|c|c|}
\hline$t$ & $w(\mathrm{AMP})$ & $\sigma_{t}^{a}$ & \\
\hline${ }^{\circ} \mathrm{C}$ & $\mathrm{g} \cdot(\mathrm{g} \text { total })^{-1}$ & ${ }^{\circ} \mathrm{C}$ & $\mathrm{SF}^{b}$ \\
\hline-0.57 & 0.0249 & 0.01 & ice \\
\hline-1.86 & 0.0745 & 0.02 & ice \\
\hline-1.746 & 0.0746 & 0.006 & ice \\
\hline-3.734 & 0.148 & 0.004 & ice \\
\hline-3.767 & 0.1491 & 0.007 & ice \\
\hline-3.96 & 0.1553 & 0.018 & ice \\
\hline-3.92 & 0.1555 & 0.016 & ice \\
\hline-6.661 & 0.2249 & 0.007 & ice \\
\hline-6.70 & 0.2257 & 0.01 & ice \\
\hline-8.49 & 0.2592 & 0.02 & ice \\
\hline-10.51 & 0.2953 & 0.05 & ice \\
\hline-10.95 & 0.2992 & 0.01 & ice \\
\hline-18.53 & 0.3801 & 0.09 & ice \\
\hline-30.0 & 0.4434 & 0.25 & ice \\
\hline
\end{tabular}

${ }^{a}$ Standard deviation of three to five consecutive analyses. ${ }^{b}$ Solidphase type.

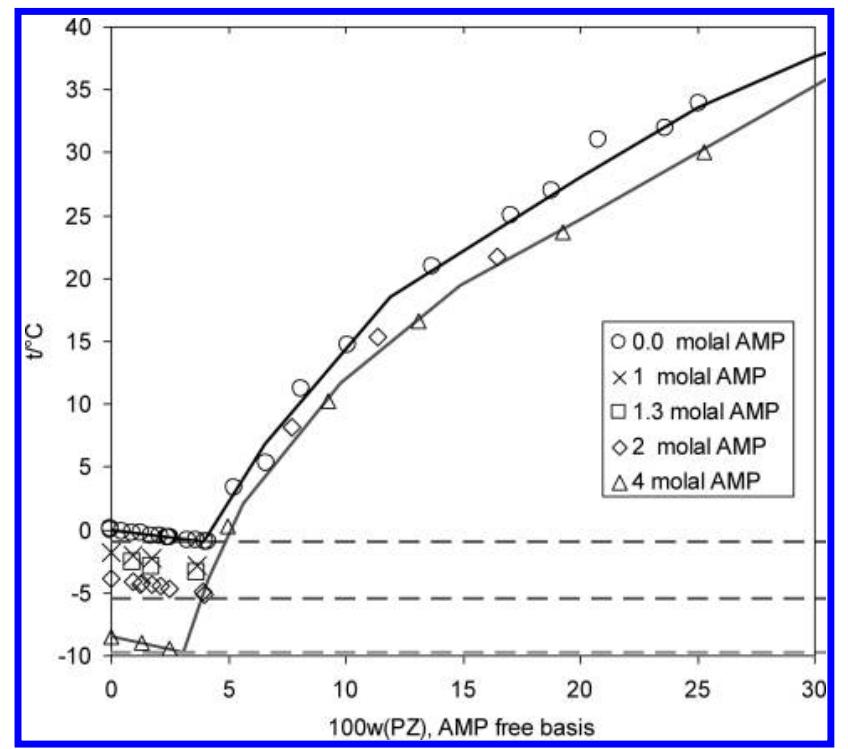

Figure 4. SLE diagram for the ternary $\mathrm{AMP}-\mathrm{PZ}-\mathrm{H}_{2} \mathrm{O}$ system as a function of temperature at atmospheric conditions. Lines indicate the trend of the data for the PZ- $\mathrm{H}_{2} \mathrm{O}$ system and the PZ-AMP $-\mathrm{H}_{2} \mathrm{O}$ system with $4 m$ AMP.

in Table 2. The table presents the solubilities determined from FPD analysis. In addition, the standard deviations and solid phase information are given. The accuracy is similar to the $\mathrm{PZ}-\mathrm{H}_{2} \mathrm{O}$ system, giving a standard deviation better than $0.01 \mathrm{~K}$. The concentrated solution for $w(\mathrm{AMP})>0.3$ become highly viscous and difficult to stir, which results in lower accuracy of the FPD determination up to $0.2 \mathrm{~K}$ in standard deviation.

The phase boundary phenomenon of the AMP $-\mathrm{H}_{2} \mathrm{O}$ system is less complicated compared to the aqueous $\mathrm{PZ}$ system. There were no indications of hydrate formation at $t>-35^{\circ} \mathrm{C}$. There is a complete lack of SLE data for comparison, and there is a need 
Table 3. Solubility in the Ternary AMP-PZ-Water System as a Function of Temperature at Atmospheric Conditions Determined by FPD and the SLE by FPD Methods

\begin{tabular}{|c|c|c|c|c|c|c|c|c|c|}
\hline$t$ & $w(\mathrm{AMP})$ & $w(\mathrm{PZ})$ & $\sigma_{t}^{a}$ & & $t$ & $w(\mathrm{AMP})$ & $w(\mathrm{PZ})$ & $\sigma_{t}^{a}$ & \\
\hline${ }^{\circ} \mathrm{C}$ & $\mathrm{g} \cdot(\mathrm{g} \text { total })^{-1}$ & $\mathrm{~g} \cdot(\mathrm{g} \text { total })^{-1}$ & ${ }^{\circ} \mathrm{C}$ & $\mathrm{SF}^{b}$ & ${ }^{\circ} \mathrm{C}$ & $\mathrm{g} \cdot(\mathrm{g} \text { total })^{-1}$ & $\mathrm{~g} \cdot(\mathrm{g} \text { total })^{-1}$ & ${ }^{\circ} \mathrm{C}$ & $\mathrm{SF}^{b}$ \\
\hline-2.011 & 0.0754 & 0.00881 & 0.006 & ice & -4.874 & 0.1503 & 0.0332 & 0.007 & ice \\
\hline-2.246 & 0.0784 & 0.0160 & 0.006 & ice & -5.11 & 0.1501 & 0.0337 & 0.018 & ice \\
\hline-2.80 & 0.0790 & 0.0340 & 0.015 & ice & 8.2 & 0.1453 & 0.0659 & 0.16 & $\mathrm{PZ} \cdot 6 \mathrm{H}_{2} \mathrm{O}$ \\
\hline-2.58 & 0.0975 & 0.00860 & 0.013 & ice & 15.3 & 0.1403 & 0.0980 & 0.17 & $\mathrm{PZ} \cdot 6 \mathrm{H}_{2} \mathrm{O}$ \\
\hline-2.88 & 0.1009 & 0.0156 & 0.01 & ice & 21.7 & 0.1333 & 0.1425 & 0.21 & $\mathrm{PZ} \cdot 6 \mathrm{H}_{2} \mathrm{O}$ \\
\hline-3.36 & 0.1000 & 0.0332 & 0.02 & ice & -8.98 & 0.2567 & 0.00958 & 0.023 & ice \\
\hline-4.086 & 0.1484 & 0.00812 & 0.005 & ice & -9.45 & 0.2543 & 0.0185 & 0.017 & ice \\
\hline-4.311 & 0.1537 & 0.0107 & 0.009 & ice & 0.25 & 0.2494 & 0.0375 & 0.057 & ice \\
\hline-4.24 & 0.1538 & 0.0108 & 0.014 & ice & 10.237 & 0.2410 & 0.0702 & & $\mathrm{PZ} \cdot 6 \mathrm{H}_{2} \mathrm{O}$ \\
\hline-4.293 & 0.1477 & 0.0148 & 0.007 & ice & 16.658 & 0.2331 & 0.1007 & 0.006 & $\mathrm{PZ} \cdot 6 \mathrm{H}_{2} \mathrm{O}$ \\
\hline-4.47 & 0.1528 & 0.0177 & 0.027 & ice & 23.65 & 0.2203 & 0.1501 & 0.01 & $\mathrm{PZ} \cdot 6 \mathrm{H}_{2} \mathrm{O}$ \\
\hline-4.67 & 0.1521 & 0.0208 & 0.01 & ice & 30.0 & 0.2073 & 0.2002 & 0.09 & $\mathrm{PZ} \cdot 6 \mathrm{H}_{2} \mathrm{O}$ \\
\hline
\end{tabular}

for detailed DSC analysis of the complete phase boundary. The solubility was not measured below $-35^{\circ} \mathrm{C}$ due to limitations by the used ice bath.

3.3. AMP $-\mathrm{PZ}-\mathrm{H}_{2} \mathrm{O}$ System. The freezing points of the ternary mixtures are shown in Figure 4 as laid out in Table 3. The information given is in accordance with Tables 1 and 2 . The SLE curve of the binary $\mathrm{PZ}-\mathrm{H}_{2} \mathrm{O}$ system corresponding to Figure 2 is included in this figure. The effect of the addition of AMP is marked by the consecutive series of data for $b(\mathrm{AMP})=\left(1.0,1.3,2.0\right.$, and 4.0) $\mathrm{mol} \mathrm{AMP} \cdot \mathrm{kg}^{-1} \mathrm{H}_{2} \mathrm{O}$. The freezing points of the solutions decrease on addition of AMP. At $b(\mathrm{AMP})=2.0 \mathrm{~mol} \mathrm{AMP} \cdot \mathrm{kg}^{-1} \mathrm{H}_{2} \mathrm{O}$ the FPD of AMP in aqueous $\mathrm{PZ}$ is approximately $(4.1$ and 8.5$) \mathrm{K}$ at $b(\mathrm{AMP})=4.0$. AMP and PZ have an observed and expected effect similar to the MEA and MDEA $^{16}$ whereby both chemicals induce FPD in the aqueous system. The recommendations for avoiding precipitation in the ternary system are equivalent to those for the aqueous PZ system as discussed above. Solid formation may only be completely prevented by using $\mathrm{PZ}$ concentrations below $w(\mathrm{PZ})<0.04$ above $0{ }^{\circ} \mathrm{C}$. There is a need for additional experimental data to perform a comparison for the reproducibility of the measured data since no other works are available. Further, measurements of solubility in highly concentrated solutions above a $w(\mathrm{PZ}, \mathrm{AMP}$ free $)=0.25$ concentration are needed.

Thermodynamic modeling is currently being done in a more intensive study on $\mathrm{PZ}$ phase equilibria.

\section{CONCLUSION}

In this work the solubility in aqueous PZ, AMP, and PZ-AMP systems was determined by freezing-point measurements and by titration. An additional new method for solubility determination based on the visual polythermal approach was developed and applied in this work. This method can be called SLE by FPD. It extends freezing-point determination to other solids than ice.

A total of 86 new data points were determined in the temperature range $(-35$ to 90$){ }^{\circ} \mathrm{C}$. This was done with the intention to study precipitation and slurry formation in relation to carbon capture and sequestration. This type of studies is relevant for the reduction of greenhouse gas emissions. The data were measured to improve the basis for thermodynamic modeling of the system. There is a general lack of this type of data in the literature; further analyses of the SLE phenomenon in these systems are needed.

The effect of $\mathrm{CO}_{2}$ loading may contribute to the formation of solids in the system, and it is important to be aware of the possible effects by dissolved $\mathrm{CO}_{2}$. In this work the unloaded solvent was studied to identify a safe range of solvent concentrations for formulation and handling.

\section{AUTHOR INFORMATION}

\section{Corresponding Author}

*Tel.: +45 4525 2800. Fax: +45 4588 2258. E-mail address: plf@kt.dtu.dk.

\section{Funding Sources}

We acknowledge the valuable consortium funding to the Center for Energy Resources Engineering (CERE) enabling the maintenance of an efficient lab at CERE.

\section{REFERENCES}

(1) FDA. Oral dosage from new animal drugs; piperazine. Fed. Regist. 1999, 64 (82), 23017-23019.

(2) Bellander, T.; Osterdahl, B. G.; Hagmar, L. Formation of $\mathrm{N}$-mononitrosopiperazine in the stomach and its excretion in the urine after oral intake of piperazine. Toxicol. Appl. Pharmacol. 1985, 80 (2), 193-8.

(3) Berthelot, M. Investigations over the Diamines: Diethyl Diamine (Piperazine). C. R. Hebdomad. Seances Acad. Sci. 1899, 129, 687-94.

(4) Rosso, J. C.; Carbonnel, L. Water-Piperazine System. C. R. Hebdomad. Seances Acad. Sci., Ser. C 1974, 278 (5), 307-309.

(5) Carbonnel, L.; Rosso, J. C. New Nitrogen Heterocycles Crystallizing as Cubic Clathrate Hydrates. Stoichiometry of the New Phases as Deduced from the Water-Heterocycle Phase Diagrams. Bull. Soc. Chim. Fr. 1976, 7-8 (Pt. 1), 1043-50.

(6) Schwarzenbach, D. Structure of Piperazine Hexahydrate. I. Chem. Phvs. 1968, 48 (9), 4134-4140.

(7) Witschonke, C. R. Freezing Point and Purity Data for Some Organic Compounds. Anal. Chem. 1954, 26 (3), 562.

(8) Hetzer, H. B.; Robinson, R. A.; Bates, R. G. Dissociation Constants of Piperazinium Ion and Related Thermodynamic Quantities from 0 to $50^{\circ} \mathrm{C}$. I. Phvs. Chem. 1968, 72 (6), 2081-2086. 
(9) Bishnoi, S. Carbon Dioxide Absorption and Solution Equilibrium in Piperazine Activated Methyldiethanolamine. Ph.D. Dissertation, University of Texas, Austin, TX, 2000.

(10) Bishnoi, S.; Rochelle, G. T. Thermodynamics of Piperazine/ Methyldiethanolamine/Water/Carbon Dioxide. Ind. Eng. Chem. Res. 2002, 41 (3), 604-612.

(11) Muhammad, A.; Abdul Mutalib, M. I.; Murugesan, T.; Shafeeq, A. Thermophysical Properties of Aqueous Piperazine and Aqueous (N-Methyldiethanolamine + Piperazine) Solutions at Temperatures (298.15 to 338.15) K. I. Chem. Eng. Data 2009, 54, 2317-2321.

(12) Hilliard, M. A. Predictive Thermodynamic Model for an Aqueous Blend of Potassium Carbonate, Piperazine, and Monoethanolamine for Carbon Dioxide Capture from Flue Gas. Ph.D. Dissertation, University of Texas, Austin, TX, 2008.

(13) Bishnoi, S.; Rochelle, G. T. Absorption of Carbon Dioxide into Aqueous Piperazine: Reaction Kinetics, Mass Transfer and Solubility. Chem. Eng. Sci. 2000, 55, 5531-5543.

(14) Bishnoi, S.; Rochelle, G. T. Absorption of Carbon Dioxide in Aqueous Piperazine/ Methyldiethanolamine. AIChE J. 2002, 48 (12), 2788-2799.

(15) Ermatchkov, V.; Pérez-Salado Kamps, Á.; Maurer, G. Chemical Equilibrium Constants for the Formation of Carbamates in (Carbon Dioxide + Piperazine + Water) from ${ }^{1} \mathrm{H}-\mathrm{NMR}-$ Spectroscopy. J. Chem. Thermodvn. 2003, 35 (8), 1277-1289.

(16) Fosbøl, P. L.; Pedersen, M. G.; Thomsen, K. Freezing Point Depressions of Aqueous MEA, MDEA, and MEA-MDEA Measured with a New Apparatus. J. Chem. Eng. Data 2011, 56, 995-1000.

(17) Fosbøl, P. L.; Thomsen, K.; Stenby, E. H. Solubility Measurements in the Mixed Solvent Electrolyte System $\mathrm{Na}_{2} \mathrm{CO}_{3}-\mathrm{NaHCO}_{3}$ Monoethylene Glycol-Water. Ind. Eng. Chem. Res. 2009, 48 (4), 22182228.

(18) Fosbøl, P. L.; Thomsen, K.; Stenby, E. H. Reverse Schreinemakers Method for Experimental Analysis of Mixed-Solvent Electrolyte Systems. J. Solution Chem. 2009, 38 (1), 1-14.

(19) Cullinane, J. T. Carbon Dioxide Absorption in Aqueous Mixtures of Potassium Carbonate and Piperazine. M.S. Thesis, University of Texas, Austin, TX, 2002. 